University of Arkansas, Fayetteville

ScholarWorks@UARK

$11-10-2017$

\title{
Gender Gaps in Math Performance, Perceived Mathematical Ability and College STEM Education: The Role of Parental Occupation
}

\author{
Lina Anaya \\ University of Arkansas, Fayetteville \\ Frank P. Stafford \\ University of Michigan - Ann Arbor \\ Gema Zamarro \\ University of Arkansas, Fayetteville
}

Follow this and additional works at: https://scholarworks.uark.edu/edrepub

Part of the Educational Assessment, Evaluation, and Research Commons, Educational Leadership Commons, and the Other Educational Administration and Supervision Commons

\section{Citation}

Anaya, L., Stafford, F. P., \& Zamarro, G. (2017). Gender Gaps in Math Performance, Perceived Mathematical Ability and College STEM Education: The Role of Parental Occupation. Education Reform Faculty and Graduate Students Publications. Retrieved from https://scholarworks.uark.edu/edrepub/57

This Article is brought to you for free and open access by the Education Reform at ScholarWorks@UARK. It has been accepted for inclusion in Education Reform Faculty and Graduate Students Publications by an authorized administrator of ScholarWorks@UARK. For more information, please contact scholar@uark.edu. 


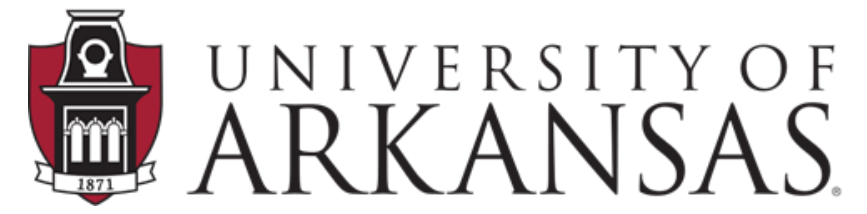

College of Education \& Health Professions Education Reform

\title{
WORKING PAPER SERIES
}

\section{Gender Gaps in Math Performance, Perceived Mathematical Ability and College STEM Education: The Role of Parental Occupation}

\author{
Lina M. Anaya, Frank P. Stafford, and Gema Zamarro
}

November, 2017

EDRE Working Paper 2017-21

The University of Arkansas, Department of Education Reform (EDRE) working paper series is intended to widely disseminate and make easily accessible the results of EDRE faculty and students' latest findings. The Working Papers in this series have not undergone peer review or been edited by the University of Arkansas. The working papers are widely available, to encourage discussion and input from the research community before publication in a formal, peer reviewed journal. Unless otherwise indicated, working papers can be cited without permission of the author so long as the source is clearly referred to as an EDRE working paper. 


\title{
char.asse $\cdot$ in
}

THE CHARACTER ASSESSMENT INITIATIVE

Gender Gaps in Math Performance, Perceived Mathematical Ability and College STEM Education: The Role of Parental Occupation

\author{
Lina M. Anaya \\ University of Arkansas \\ Frank P. Stafford \\ University of Michigan \\ Gema Zamarro* \\ University of Arkansas
}

November 2017

*Correspondence author: Gema Zamarro, University of Arkansas, 219B Graduate Education Building, Fayetteville, Arkansas, 72701, phone: 479-575-7024, email: gzamarro@uark.edu. 


\begin{abstract}
Employment opportunities in occupations related to Science, Technology, Engineering, and Mathematics, the so-called STEM fields, are predicted to continue growing through time. In addition, STEM occupations also enjoy higher wages on average. Despite these advantages, women remain under-represented in STEM college degree completion and occupations. Encouraging women into the STEM fields has become an important policy concern. We use longitudinal data from the Panel Study of Income Dynamics to study gender differences in math achievement and self-perceived math ability and how they may differ by parental occupation type, specifically science related versus non-science related parental occupations. We then study their role on subsequent decision of majoring in a science field in college. Our results corroborate significant gender differences in math test scores and perceived math ability during childhood. Having a parent working in a science related field is associated with a better performance in math but not necessarily higher levels of perceived math ability, given math performance. All three factors, math achievement, perceived math ability, and parental occupation in a science field, are found to be significant predictors of the probability of majoring in science in college. However, estimated effects of higher levels of math achievement are about double for boys than for girls. Estimates of perceived math ability are also slightly larger for boys. In contrast, most of the observed positive effects of having a parent in a science related occupation seem to be concentrated among females. These results suggest a loss in STEM enrollment by otherwise qualified young women and the potential importance that parental role modeling effects or specific human capital parental investments by parents in science occupations could have for encouraging women to major in science fields.
\end{abstract}

Keywords: STEM gender gaps; perceived ability; self-efficacy; college major; parental occupations.

JEL codes: J16, I20, J62 


\section{Introduction}

Employment opportunities in occupations related to Science, Technology, Engineering, and Mathematics, the so-called STEM fields, are projected to continue to grow through time. According to the U.S Bureau of Labor Statistics (2014), employment in STEM occupations are expected to grow by about one million jobs between 2012 and 2022. In addition, wages in STEM occupations, although with considerable variation, are estimated to be on average nearly double the national average wage for non-STEM jobs, and so, improving women's representation in STEM occupations is seen as a potential way of reducing persistent gender wage gaps.

Despite these prospects and the growth on female labor participation, women remain under-represented in STEM college degree completion and occupations. Using data from the Census Bureau's 2009 American Community Survey, Beede et al. (2011) showed that women held less than 25 percent of STEM jobs, despite holding about 48 percent of all jobs. This is especially problematic when looking at the "hard sciences" STEM fields of engineering, information technology, computer science and mathematical occupations and less so for a wider definition of STEM sciences, to also include Life, Physical and Social Sciences. For the later science occupations, the share of women has risen and higher wages in these fields have helped women improve their occupational wage ranking ( $\mathrm{Li}$ and Stafford, 2017).

Motivated by the prospects of economic growth that could be derived from the expansion of a labor force with the necessary skills for STEM related occupations, encouraging women into the STEM fields has become an important policy concern. However, a necessary first step for this aim is to gain a better understanding of the drivers of such gender gap in STEM. Only then, one would be able to prescript effective policy proposals that could help reduce it.

In this paper, we use data from the Child Development Supplement (CDS) and Transition to Adulthood (TA) projects in the Panel Study of Income Dynamics (PSID). The PSID is a longitudinal household survey and the CDS and TA project data allow us to study the presence of gender differences, during childhood and then as the children become young adults age 18-25. The CDS includes measures of math achievement and of self-perceived math ability. By linking to the occupations of the children's parents, it is possible to study how the children's measures differ by 
parental occupation type. Notably, do the parents work in STEM versus non-STEM occupations and how does it relate to math test performance and self-perceptions of math ability. We then study the relationship of these factors to the subsequent decision of majoring in a STEM field in college.

The rest of the paper is organized as follows. Section 2 describes the related literature on potential factors driving gender differences in STEM. In Section 3 we present an overview of the data from the PSID that we use in this analysis. In Section 4, we present descriptive results on observed gender differences in math achievement and perceived math ability during childhood and to what extend they might be shaped by parental occupation in a science field. Section 5 presents our models of the relationship between math achievement, perceived math ability, parental science occupation and the likelihood of majoring in a science field in college. Section 6 presents a summary and conclusions.

\section{Selected Literature Review}

Scholars have argued that gaps in math performance are an important factor affecting STEM outcomes and that they begin early in elementary school. Robinson and Lubienski (2011), using data from the Early Childhood Longitudinal Study, Kindergarten Class of 1998-1999, showed that girls and boys enter kindergarten with similar levels of math ability but a gap in math performance, favoring boys, is observed as early as first grade. This gap is found to be particularly pronounced among those on the top part of the math test score distribution. Although girls are found to catch some ground over the middle school years, the authors reported that a gender gap in math performance was still persistent at the end of $8^{\text {th }}$ grade.

Persistent gender gaps in math performance could limit girls' options to access advanced math courses and subsequent access to upper-secondary education in science fields. However, Niederle and Verterlund (2010) argued that these observed gender gaps in math performance could be due in part to the differential way men and women approach competitive test-taking environments and might not fully reflect actual gender differences in math skills. At the high school level, research is not conclusive on the degree to which there are gender differences in the level of investment in math courses. Although gender differences are still observed in enrollment in specific science Advance Placement (AP) courses in high school ${ }^{1}$, e.g. AP mathematics (calculus and statistics) or

\footnotetext{
${ }^{1}$ See data for 2009-2010 here: https://www2.ed.gov/about/offices/list/ocr/docs/gender-equity-in-education.pdf
} 
AP physics, girls are found to enroll in AP science courses at a higher rate than boys. Using administrative data from Canadian students, Card and Payne (2017) argued that gender differences in the type of courses high-achieving students take in high school had a modest effect on explaining gender gaps in STEM majors in college. They argued that the fact that many more non-STEM oriented women entered university than men, as a result of different course choices early on at high school, helped explain a bigger share of the STEM gap in college. Similarly, Goldin, Katz, and Kuziemko (2006) found no gender differences in advanced math class enrollment among the 2000 high school graduating cohort, and Guiso, Monte, Sapienza, and Zingales (2008) found that girls reported spending more time on their math homework than boys. More clear differences in math investments are observed at the college level. For instance, Weinberger (2005) found that, among students with the same level of math test performance, males were much more likely to select college majors high in math content and that women entered the STEM majors at no more than half the rate of men with the same math scores.

New research on gender economics has highlighted the potential role of psychological factors in explaining gender differences in labor outcomes (Bertrand, 2010). Along these lines, researchers in educational psychology have pointed out the potential role that gender differences in perceived math ability could have in explaining the underrepresentation of women in STEM courses, college majors and occupations. Nix et al. (2015) and Perez-Felker et al. (2017) showed that, among high school students, boys exhibited higher levels of perceived math ability than girls and that higher levels of perceived math ability significantly predicted the likelihood of enrolling in mathematically-intensive courses in high school and majoring in those fields during college, even after controlling for math achievement levels.

An important factor, less studied in the STEM gender gap literature, is the potential role of parental occupation type. Parent's occupations could affect children's STEM choices in multiple ways. Higher wages in STEM related occupations could lead to higher monetary investments in children human capital development. Parents in STEM fields might also differ in the type of educational activities they promote in their children which could help shape their preferences and potentially help reduce gender stereotypes towards STEM fields. Parents with a STEM occupation could serve as role models for their children and finally, they could help 
promoting social networks and specific job knowledge, increasing the potential returns to achieving a STEM college degree. While there is some regression to the mean observed across generations in terms of both earnings and occupational type, with the highest parental occupations leading to lower occupational achievement of children, there is substantial carry over still observed across generations ( $\mathrm{Li}$ and Stafford, 2017) and a rising impact of work content shifting toward quantitative skills (Black and Spitz-Oener, 2010).

To connect to family influences on occupational choice, Nollenberger and RodriguezPlanas (2017), using data from the PISA study, find that parents views on gender social norms influence their children's academic motivation and that this then manifest in different student performance on math and science tests. Similarly, research has found that children whose parents believe that math and science are important for subsequent education and future employment are more likely to have higher math test scores and enroll in more math and science courses in high school (Giannelli and Rapallini, 2017; Harackiewicz et al., 2012). These attributes are potentially very different for parents in science related and non-science related occupations. Finally, Cheng et. al. (2017) found that parental role modeling effects, through the type of occupation they hold, could be especially important for women's long term STEM outcomes, i.e. graduating from a STEM major and working on a STEM profession, and that they could help eliminate observed gender gaps in STEM.

This paper builds on this previous work and contributes to the literature by bringing together all these factors to study their role in explaining college decisions of majoring in a science related field. We document gender gaps in math achievement and perceived math ability during childhood and how these may differ by parental occupation type. We also study the role of these factors along with parental occupation, and study potential differential effects by gender on influencing the probability of majoring in science in college. Notably, we explore the relationship between gender and applied problems math test scores as the two jointly relate to majoring in science in college.

\section{Data and Descriptive Statistics}

For our analysis, we use data from the Panel Study of Income Dynamics (PSID). The PSID is a longitudinal household survey, which began on 1968 with 18,000 individuals living in 
5,000 households in the United States. The PSID sample size has continued to increase over time as the descendants from the original households move out to form their own households and are invited to join the study. Respondents are then followed over time, regardless of address changes. This longitudinal survey includes information on family composition changes, housing and food expenditures, marriage and fertility histories, employment, income, health, household consumption, among other topics.

Additionally, the PSID has collected, over time, complementary data on specific populations to gather additional information. Of especial interest for this paper is the data collected through the Child Development Supplements (CDS) of the PSID. In 1997, the PSID collected supplemental information on, up to two, 0-12 year-old, children from PSID families with the objective of obtaining a nationally representative and longitudinal dataset of children to study the human capital formation process. 2,398 families were contacted at this point including 3,563 children. In 2002-2003, families that were part of the 1997 CDS were recontacted if they remained active in the panel as of 2001. Families were re-contacted once more in 2007-2008. Using these follow up surveys, data was collected of PSID children up to age 18. Finally, a new cohort of the CDS began in 2014.

Another important supplemental PSID dataset for our analysis comes from the Youth's Transition into Adulthood (TA) study. A complementary dataset designed to follow CDS participants in the time between they age out of the supplement at 18 and before they form their own household, usually on average at age 24. Therefore, the PSID is able to track children targeted at each CDS through up to 3 CDS supplemental surveys and then biennially from age 18 to 24 under the TA study, and then at around 25 or whenever they form their own household as new core members of the PSID.

For this study we exploit the family structure in the PSID and combine information of the following surveys: Information about children from PSID members through the Child Development Supplement 2002 (CDS-2002), information of these children's college education through the Transition into Adulthood Supplement 2013 (TA-2013) and Transition into Adulthood Supplement 2015 (TA-2015), and children demographic and information about 
parents $^{2}$ through the PSID individual data 2001 (PSID-2001) and PSID Main Family Data 2003 (PSID-2003).

Our key variables from the CDS-2002 include measures of math ability through standardized Woodcock Jonson applied problems test (W-J AP) scores ${ }^{3}$ and a measure of selfreported perceived math ability. Children, 6 years of age and older, in the sample, were asked to report on a scale of 1 to 7 from "not at all good" to "very good" on how good at math they consider themselves to be. Using this information, along with sampling weights, we built weighted percentiles of the W-J AP test scores and then, in order to present the empirical relationships, children were classified into three levels: Level 1 for those scoring between the 0 and 50 percentile; Level 2 for those scoring between the 51 and 80 percentile; and Level 3 for those performing between the 81 and 100 percentile. Similarly we created levels of perceived math ability and classified children in our sample in three groups: Level 1 for those reporting levels of perceived math ability between 1 and 3; Level 2 for those reporting levels between 4 and 5; and Level 3 for those reporting levels of perceived math ability of 6 and 7 .

From the TA-2013 and TA-2015 we capture information about college attendance and main major of study in college. With this information we created a dummy variable for college major in "hard sciences" STEM, including engineering, architecture, mathematical and computer sciences. We also created a wider definition of STEM science major with a dummy that included all the above majors plus life, physical and social sciences (e.g. physics, chemistry and biology majors, medical sciences, dentistry, veterinarian, nursing, physical therapy, sports medicine, pharmacy and sports management, economics, business and other social sciences).

\footnotetext{
2 Technically, our occupational information refers to the head of the household and spouse and these could be different from the parents of the child. However, most of the cases ( $88 \%$ of cases) the child is son or daughter of the head of the household or spouse and so, we refer to this variable as parental occupation. The remaining cases represent situations where the child is a stepson or stepdaughter of the head of the household, the head or spouse is a grandparent or the child lives with other relatives.

3 The W-J AP test is a nationally-normed standardized assessment of mathematical thinking developed for ages 2 to 90. For more information on the W-J AP test and other tests administered in the CDS module of the PSID see: https://psidonline.isr.umich.edu/publications/Papers/tsp/2014-02_Achievement.pdf
} 
Finally, parental occupation information comes from the PSID-2003. Occupation type is coded following the 3-digit code index of industries and occupations, from the 2000 census of population and housing, issued by the U.S Department of Commerce and the Census Bureau. With this information we created a dummy variable indicating whether the head of the household or the spouse, at least one of them, reported having worked in a "hard science" STEM occupation ${ }^{4}$, i.e. computer sciences, mathematics, physics, architecture or engineering occupations. We also added a dummy variable for the head of the household or the spouse having worked on a science occupation, using a wider definition of STEM science, which also included life, physical and social sciences occupations ${ }^{5}$. These type of occupation classifications relatively align with our definition of college STEM majors described above.

Table 1 presents descriptive statistics for our analytical sample. Our sample includes 2,158 observations of children with valid W-J AP scores and reported math ability, with about half the sample representing males and the other half females. Information on math performance and perceived math ability was collected through the CDS 2002 sample when the children on average were around 11 years old ${ }^{6}$. College major information is observed through the TA 2013 or TA 2015 modules when the children in the sample were on average 23 and 25 years old. We found small but statistically significant differences in age for boys and girls in our sample with girls being slightly older. Girls in our sample present statistically significant lower average performance on the W-J AP test, when measured during childhood, and report significantly lower average levels of perceived ability in math at this time. In the next section, we further study these patterns of math achievement and perceived math ability, paying especial attention to the role of parental occupation type.

\footnotetext{
${ }^{4}$ In the 2000 classification, these were occupations within the codes of 100-156.

${ }^{5}$ In the 2000 classification, these were occupations within the codes 160-196.

${ }^{6}$ Math performance through the W-J AP scores are adjusted for age.
} 


\section{Table 1: Analytical Sample Summary Statistics}

\begin{tabular}{|c|c|c|}
\hline & Female & Male \\
\hline Gender (\%) & 50.3 & 49.7 \\
\hline \multicolumn{3}{|l|}{ Age (years) } \\
\hline CDS 2002 & 11.3 & 11.1 \\
\hline [Min-Max] & {$[6-17]$} & [6-17] \\
\hline TA 2013 & 23.4 & 23.1 \\
\hline [Min-Max] & [18-29] & [18-29] \\
\hline TA 2015 & 25.5 & 25.2 \\
\hline [Min-Max] & {$[20-31]$} & [20-31] \\
\hline W-J AP Test scores & 103.5 & 107.1 \\
\hline Perceived Math Ability & 4.6 & 5.1 \\
\hline \multicolumn{3}{|l|}{ Parental occupation } \\
\hline All Sciences & $7.0 \%$ & $7.1 \%$ \\
\hline Hard Sciences & $5.5 \%$ & $5.6 \%$ \\
\hline Other Occupations & $92.9 \%$ & $92.9 \%$ \\
\hline \multicolumn{3}{|l|}{ College Major } \\
\hline All Sciences & $30.6 \%$ & $28.6 \%$ \\
\hline Hard Sciences & $2.9 \%$ & $9.5 \%$ \\
\hline Other Majors & $26.4 \%$ & $18.5 \%$ \\
\hline No College Educ. & $42.9 \%$ & $52.8 \%$ \\
\hline N. Observations & 1,067 & 1,091 \\
\hline
\end{tabular}

Overall, we do not find statistically significant differences on the type of parental occupation by gender. 7 percent of both boys and girls in our sample have at least one parent or guardian who report working on a science related occupation. Of these, 5 percent report working on an occupation related to "hard sciences" STEM field. Finally, when we look at the type of college major declared by the children in our sample we do start to observe significant gender differences. Although both boys and girls seem to be majoring at the same rates in STEM fields, when we consider a wide definition of science, girls are much less likely to major in the "hard sciences" STEM field than boys. On average, about 30 percent of both boys and girls declare a major in science but only about 3 percent of girls do it in a "hard sciences" 
STEM field, while almost 10 percent of boys do so. On average, girls tend to major more in non-science fields, 8 percent more girls than boys do so. Finally, we observe that, on average, girls attend college in a higher proportion than boys in our sample, with almost 53 percent of boys not being observed attending college as compared to 43 percent of girls. Higher college enrollment for young women is not a surprising result. Patterns of college attendance and graduation having become higher for women have been previously reported in the literature (Goldin et al., 2006).

\section{Gender Differences in Math Test Performance and Perceived Ability}

Table 2 describes patterns on performance on the Woodcock Johnson Applied Problems test as well as self-reported perceived math ability, by gender. Both math performance and perceived math ability are classified in three groups representing low, medium and high levels, as described in the data section above. The diagonals of these figures represent the percentage of children that could be considered reporting a perceived ability approximately on target with their math performance. That is, those reporting low levels of math ability while performing on the lower percentiles of the W-J AP test, reporting medium levels of ability and performing on the middle of the math test distribution or reporting higher levels of ability and performing on the highest percentiles of the W-J AP test.

We observe interesting patterns of math performance and self-reported ability in this table, by gender. As described below, boys present higher levels of performance on the W-J AP test than girls. This is so, because a higher proportion of boys in our sample performs in the middle and higher end of the test distribution, while a higher proportion of girls performs on the lower percentiles. Similarly, girls tend to report lower levels of perceived math ability than boys. This is so as girls tend to use more the medium and lower levels of the perceived math ability scale and less the higher levels of math ability. In general, boys tend to report levels of math ability that are more on target, given W-J AP performance; 34 percent of boys report in the highlighted diagonal as compared with 31 percent of girls. Conditional on a high W-J AP score, girls are less likely to have a self-rating math ability of 6-7. Overall, girls are more likely to report a middle range for perceived math ability than boys. 
Table 2: W-J AP performance and Perceived Math Ability (\% of sample)

\begin{tabular}{|c|c|c|c|c|}
\hline Boys & \multicolumn{3}{|c|}{ Perceived Math Ability } & \multirow[b]{2}{*}{ Total } \\
\hline W-J AP (percentile) & 1 to 3 & 4 to 5 & 6 to 7 & \\
\hline $0-50$ & 8.04 & 27.85 & 14.65 & 50.54 \\
\hline $51-80$ & 1.10 & 11.90 & 13.83 & 26.83 \\
\hline 81-100 & 0.64 & 7.41 & 14.58 & 22.63 \\
\hline Total & 9.79 & 47.15 & 43.06 & 100.00 \\
\hline
\end{tabular}

Girls

\begin{tabular}{|c|c|c|c|c|}
\hline \multirow[b]{2}{*}{ W-J AP (percentile) } & \multicolumn{4}{|c|}{ Perceived Math Ability } \\
\hline & 1 to 3 & 4 to 5 & 6 to 7 & Total \\
\hline $0-50$ & 11.62 & 39.76 & 10.59 & 61.97 \\
\hline $51-80$ & 1.45 & 11.10 & 9.69 & 22.24 \\
\hline $81-100$ & 0.73 & 7.14 & 7.93 & 15.80 \\
\hline Total & 13.79 & 58.00 & 28.21 & 100.00 \\
\hline
\end{tabular}

Next we study how these observed patterns of math performance and perceived math ability may vary with parental occupation type. Table 3 shows the same statistics that were presented in Table 2 but by parental occupation in a science field or not, using a wide definition of STEM science. Observed gender differences in math performance and self-reported ability get reduced when parents report working on a science related occupation. The gender gap in performance in the W-J AP test gets reduced from about 7 percent more boys than girls performing in the highest percentiles of the distribution, when parents don't have a science occupation, to only 3 percent more boys than girls doing so if at least one parent or guardian works in a science related field. Similarly, 17 percent more boys than girls self-report a level of math ability of 6 or 7 if parents don't work in a science related job and only 5 percent more boys do so if we compare those with parents in science occupations. In addition, having a parent that works in a science related job is found to increase the probability for both boys and girls to perform in the top percentiles of the W-J AP test distribution and of reporting the highest levels of perceived ability, but seems to do so more for boys than for girls. 
Table 3: W-J AP performance and Perceived Math Ability, By Parental Occupation Type (\% of sample)

\begin{tabular}{|c|c|c|c|c|}
\hline \multicolumn{4}{|c|}{ Boys-Parents Not in Science } & \multirow[b]{3}{*}{ Total } \\
\hline & \multicolumn{3}{|c|}{ Perceived Math Ability } & \\
\hline W-J AP (percentile) & 1 to 3 & 4 to 5 & 6 to 7 & \\
\hline $0-50$ & 7.89 & 27.86 & 14.34 & 50.09 \\
\hline $51-80$ & 1.14 & 11.68 & 15.57 & 28.39 \\
\hline 81-100 & 0.55 & 6.96 & 14.01 & 21.52 \\
\hline Total & 9.59 & 46.50 & 43.92 & 100.00 \\
\hline \multicolumn{4}{|c|}{ Boys-Parents in Science } & \\
\hline \multicolumn{5}{|c|}{ Perceived Math Ability } \\
\hline W-J AP (percentile) & 1 to 3 & 4 to 5 & 6 to 7 & Total \\
\hline $0-50$ & 12.13 & 16.79 & 6.67 & 35.60 \\
\hline $51-80$ & 0.57 & 15.72 & 1.29 & 17.59 \\
\hline 81-100 & 2.44 & 15.25 & 29.12 & 46.81 \\
\hline Total & 15.15 & 47.77 & 37.08 & 100.00 \\
\hline
\end{tabular}

Girls-Parents Not in Science

\begin{tabular}{l|l|lll} 
& \multicolumn{4}{l}{} \\
\cline { 2 - 4 } Werceived & Math Ability & \\
\hline $\mathbf{0 - 5 0}$ & $\mathbf{1}$ to 3 & $\mathbf{4}$ to $\mathbf{5}$ & $\mathbf{6}$ to $\mathbf{7}$ & Total \\
$\mathbf{5 1 - 8 0}$ & $\mathbf{1 1 . 8 6}$ & 41.00 & 10.48 & 63.34 \\
$\mathbf{8 1 - 1 0 0}$ & 1.68 & $\mathbf{1 1 . 2 4}$ & 9.65 & 22.58 \\
Total & 0.85 & 5.92 & $\mathbf{7 . 3 1}$ & 14.08 \\
\cline { 2 - 4 } & 14.39 & 58.16 & 27.45 & 100.00 \\
\hline
\end{tabular}

\begin{tabular}{|c|c|c|c|c|}
\hline \multicolumn{4}{|c|}{ Girls-Parents in Science } & \multirow[b]{3}{*}{ Total } \\
\hline & \multicolumn{3}{|c|}{ Perceived Math Ability } & \\
\hline W-J AP (percentile) & 1 to 3 & 4 to 5 & 6 to 7 & \\
\hline $0-50$ & 3.50 & 21.03 & 5.45 & 29.98 \\
\hline $51-80$ & 0.00 & 16.59 & 9.04 & 25.63 \\
\hline $81-100$ & 0.00 & 27.04 & 17.35 & 44.39 \\
\hline Total & 3.50 & 64.66 & 31.84 & 100.00 \\
\hline
\end{tabular}

To get a better insight on gender differences in perceived math ability, we next compare reported math ability levels of boys and girls performing on the same percentile groups of the $\mathrm{W}$ $\mathrm{J}$ AP test. These results are presented in Table 4. We observe important differences on reported math ability by boys and girls, especially at the tails of the W-J AP distribution. Focusing on the highest percentiles of math performance, we observe that a higher proportion of boys than girls report the highest levels of math ability, 64 percent of boys as compared to 50 percent of girls. 
Similarly, in the lower end of the math test scores distribution boys continue to be more optimistic about their math ability, with 29 percent of them still reporting the highest levels of ability as compared to 17 percent of the girls.

Table 4: Perceived Math Ability by Gender, given W-J AP scores (\% of sample)

\begin{tabular}{lllll} 
& & \multicolumn{3}{l}{ Perceived Math Ability } \\
\hline W-J AP (percentile) & Gender & $\mathbf{1}$ to 3 & $\mathbf{4}$ to $\mathbf{5}$ & $\mathbf{6}$ to $\mathbf{7}$ \\
\hline $\mathbf{0 - 5 0}$ & Boys & $\mathbf{1 5 . 9}$ & 55.1 & $\mathbf{2 9 . 0}$ \\
& Girls & $\mathbf{1 8 . 7}$ & 64.2 & 17.1 \\
\hline $\mathbf{5 1 - 8 0}$ & Boys & 4.1 & 44.3 & 51.6 \\
& Girls & 6.5 & 49.9 & 43.6 \\
\hline $\mathbf{8 1 - 1 0 0}$ & Boys & 2.8 & 32.7 & $\mathbf{6 4 . 4}$ \\
& Girls & 4.6 & 45.2 & $\mathbf{5 0 . 2}$ \\
\hline
\end{tabular}

Note: Weighted percentages reported using child population weights.

Table 5: Perceived Math Ability by Gender, given W-J AP scores (\% of sample)

Parents Not in Science

\begin{tabular}{llllc} 
& \multicolumn{4}{c}{ Perceived Math Ability } \\
\hline W-J AP (percentile) & Gender & $\mathbf{1 ~ t o ~} 3$ & $\mathbf{4}$ to $\mathbf{5}$ & $\mathbf{6}$ to $\mathbf{7}$ \\
\hline $0-50$ & Boys & $\mathbf{1 5 . 8}$ & 55.6 & $\mathbf{2 8 . 6}$ \\
& Girls & $\mathbf{1 8 . 7}$ & 64.7 & 16.6 \\
\hline $51-80$ & Boys & 4.0 & 41.2 & 54.8 \\
& Girls & 7.5 & 49.8 & 42.8 \\
\hline $81-100$ & Boys & 2.6 & 32.3 & $\mathbf{6 5 . 1}$ \\
& Girls & 6.0 & 42.1 & $\mathbf{5 1 . 9}$ \\
\hline
\end{tabular}

\section{Parents in Science}

\begin{tabular}{lllll} 
& & \multicolumn{3}{l}{ Perceived Math Ability } \\
\hline W-J AP (percentile) & Gender & $\mathbf{1}$ to 3 & $\mathbf{4}$ to 5 & $\mathbf{6}$ to 7 \\
\hline $0-50$ & Boys & 34.1 & 47.2 & 18.7 \\
& Girls & 11.7 & 70.2 & 18.2 \\
\hline $51-80$ & Boys & 3.3 & 89.4 & 7.3 \\
& Girls & 0.0 & 64.7 & 35.3 \\
\hline $81-100$ & Boys & 5.2 & 32.6 & $\mathbf{6 2 . 2}$ \\
& Girls & 0.0 & 60.9 & $\mathbf{3 9 . 1}$ \\
\hline
\end{tabular}

Note: Weighted percentages reported using child population weights. 
Finally, we also study if observed gender patterns in reporting math ability levels are different depending on the type of parental occupation (science, non-science occupations). Results are presented in Table 5. Having at least one parent or guardian working in a science related field does not seem to reduce gender differences in reported math ability once we condition on a given level of W-J AP performance. If anything, it seems that children with parents working in a science field appear to be more pessimistic about their math ability than those with parents working in other types of occupations.

\section{Math Test Performance, Perceived Ability, Parental Occupation Type and Gender Differences in College Major Choices.}

Next we describe to what extent the observed differences in math performance and perceived math ability, described in previous section, could be related to the likelihood of studying science majors in college. We also explore if there is a direct relationship of parental occupation type to the probability of a science major. The relationship thought to be arising from differential parental human capital investments or role modeling effects, derived from having at least a parent or guardian working in a STEM field. We estimate linear probability models for reporting currently studying or having studied a science major in college ("hard sciences" STEM major or wide definition of STEM major) as a function of gender, W-J AP performance, self-reported math ability and whether one of the parents or guardians worked in a science related occupation. We also study the potential of differential effects of these variables by gender with selected interaction terms. The analysis is for both "hard sciences" STEM majors and parental occupations (Table 6) as well as for a wider definition of STEM science majors and occupations (Table 7), as described in the data section above.

Table 6 presents the results when considering the probability of majoring in a "hard science" STEM field. Columns 1 and 2 present estimates for the entire sample of CDS 2002 children, independently of college enrollment status. In contrast, columns 3 and 4 present results when we condition the sample to include only those children who at least made it to enroll in college. We observe the expected gender differences in the probability of majoring in a "hard sciences" STEM field with females having on average directly about a 5 percentage points lower probability, given math performance, perceived ability and parental occupation type. The difference is even higher if we focus on those children who at least made it to enroll in college 
(column 3), with girls in this case having almost 13 percentage points lower probability of majoring in "hard sciences" fields.

Table 6: Determinants of the Probability of Majoring in a "Hard Sciences" STEM Field in
College

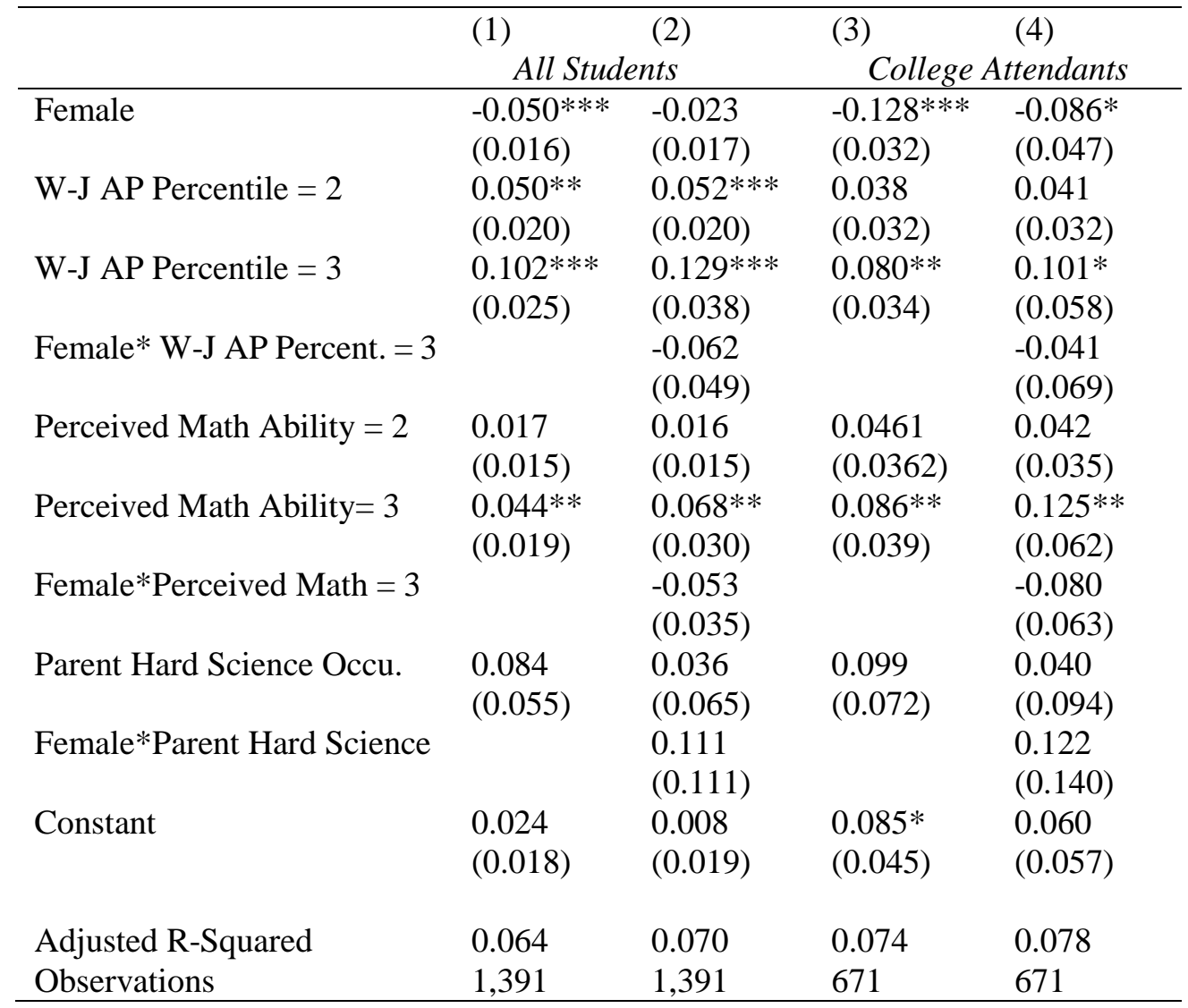

Note: Robust Standard Errors in parenthesis; *** $\mathrm{p}<0.01, * * \mathrm{p}<0.05,{ }^{*} \mathrm{p}<0.1$; Sample for estimates in (3) and (4) only include those who at least enrolled in college. Weighted estimates reported using child population weights.

Both W-J AP performance and self-perceived math ability have significant relationships to the likelihood of majoring in a "hard sciences" STEM field. However, males appear to enjoy higher returns on these attributes. Looking at column 2, we observe that for boys, performing on the highest percentiles of the W-J AP distribution, as compared to performing in the lowest percentiles, increases the probability of majoring in a "hard sciences" STEM field by about 13 percentage points while, allowing for the negative interaction term (-0.062), for girls the effect is almost half at 6 percentage points. Similarly, reporting the highest levels of perceived math ability, as compared to the lowest levels, increases the probability of majoring in a "hard sciences" STEM field by about 7 percentage points for males and, allowing for the point estimate on the female interaction term (-0.053), only 2 percentage points for females. Similar patterns of results are 
observed if we condition the sample to those who at least enrolled in college (column 4). These results suggest that not only lower levels of math performance and perceived ability might be discouraging women to enroll in hard science majors, and that maybe other attributes, not considered here, like for example, gender identity norms could be important.

Interestingly, having at least a parent or guardian who works in a science occupation could help females. We observe that overall having at least a parent in a "hard sciences" STEM occupation has a positive relationship to the likelihood of majoring in a "hard sciences" STEM field in college but this effect, although imprecisely estimated, seems to be concentrated on females and not that much on males.

Finally, Table 7 presents results using a wider definition of STEM sciences, to include not only "hard sciences" STEM fields but also life, physical and social sciences. In accordance with the descriptive statistics presented above, we observe that in this case there is no disadvantage for females majoring in science. In fact, women are about 7 percentage points more likely to major in any of these STEM fields than boys overall in the whole sample, when we use a wider definition of STEM. No significant gender difference is observed when studying only those who at least enrolled in college. Despite this, W-J AP performance and perceived math ability continue to be significant determinants of the probability of majoring in a science field and men continue to benefit more of higher values of these factors than women. Of note are the negative and statistically significant interaction coefficients in columns 2 and $4(-0.203$ and -0.251$)$ between female and high AP test scores. These suggest a loss of STEM enrollment by otherwise capable women. Finally, having at least a parent or guardian working in a STEM related occupation continues to have a positive, and in this case statistically significant, effect on the probability of majoring in science and this effect continues to be mostly concentrated among females.

\section{Discussion and Conclusion}

Despite predicted increasing labor opportunities and returns to the study in the so-called STEM fields, i.e. Science, Technology, Engineering, and Mathematics, women remain underrepresented, at least when we focus on a narrow definition of STEM and consider only the "hard sciences" STEM fields (i.e. engineering, mathematics and computer sciences). Research suggests that gender differences in math performance and perceived levels of math ability during childhood could be important factors explaining these differences. Parental occupation type, a factor that 
appear to be less studied in the STEM gender gap literature, could be an important factor reducing gender differences. Parent's views of gender social norms, differential parental investments in human capital development or direct role modeling effects could be very different depending on having a parent working on a STEM related field or not. In this paper we use longitudinal data from the PSID to study gender differences in these factors and their potential effect on the decision on majoring on a STEM field while in college.

Table 7: Determinants of the Probability of Majoring in any STEM Science in College

\begin{tabular}{lllll}
\hline & $(1)$ & $(2)$ & $(3)$ & $(4)$ \\
\hline & \multicolumn{2}{c}{ All Students } & College Attendants \\
\hline & & & & \\
Female & $0.075^{* *}$ & $0.106^{* * *}$ & -0.022 & 0.074 \\
& $(0.030)$ & $(0.035)$ & $(0.047)$ & $(0.074)$ \\
W-J AP Percentile $=2$ & $0.175^{* * *}$ & $0.176^{* * *}$ & 0.060 & 0.069 \\
& $(0.038)$ & $(0.038)$ & $(0.057)$ & $(0.057)$ \\
W-J AP Percentile =3 & $0.267^{* * *}$ & $0.356^{* * *}$ & 0.076 & $0.202^{* * *}$ \\
& $(0.043)$ & $(0.055)$ & $(0.060)$ & $(0.075)$ \\
Female*W-J AP Percent. =3 & & $-0.203^{* *}$ & & $-0.251^{* * *}$ \\
& & $(0.084)$ & & $(0.097)$ \\
Perceived Math Ability $=2$ & 0.020 & 0.017 & 0.067 & 0.061 \\
& $(0.048)$ & $(0.047)$ & $(0.097)$ & $(0.093)$ \\
Perceived Math Ability $=3$ & $0.179^{* * *}$ & $0.184 * * *$ & $0.282^{* * *}$ & $0.330 * * *$ \\
& $(0.054)$ & $(0.057)$ & $(0.098)$ & $(0.104)$ \\
Female*Math Ability $=3$ & & -0.016 & & -0.096 \\
& & $(0.067)$ & & $(0.091)$ \\
Parent Science Occupation & 0.083 & -0.039 & 0.009 & -0.147 \\
& $(0.061)$ & $(0.081)$ & $(0.073)$ & $(0.098)$ \\
Female*Parent Science & & $0.258^{* *}$ & & $0.320 * *$ \\
Constant & & $(0.121)$ & & $(0.138)$ \\
& 0.073 & 0.058 & $0.375^{* * *}$ & $0.314 * * *$ \\
Adjusted R-Squared & $(0.046)$ & $(0.045)$ & $(0.099)$ & $(0.102)$ \\
Observations & & & & \\
\hline
\end{tabular}

Note: Robust Standard Errors in parenthesis; *** p<0.01, ** $\mathrm{p}<0.05$, * $\mathrm{p}<0.1$; Sample for estimates in (3) and (4) only include those who at least enrolled in college. Weighted estimates reported using child population weights.

Our results corroborate significant gender differences in math test scores and perceived math ability during childhood. Even after conditioning in a given math test performance level, girls significantly report lower levels of perceived math ability than boys. This is especially problematic among those in the tails of the math achievement distribution. Having at least a parent or guardian working on a STEM related occupation is associated with a higher probability of performing on the highest percentiles of the math test score distribution. However, perceived math 
ability levels are not found to significantly improve by having a parent in a STEM related occupation, once math test performance is hold fixed. Finally, all three factors, math achievement, perceived math ability, and parental occupation in STEM fields, are found to be significant predictors of the probability of majoring in a STEM field in college. However, estimated effects of higher levels of math achievement and perceived math ability are higher for boys than for girls, especially for returns to W-J AP test performance. This suggests a loss in STEM enrollment by otherwise qualified young women. In contrast, most of the observed positive effects of having at least a parent or guardian in a STEM occupation seem to be concentrated among females.

Our results suggest the existence of additional barriers, other than math performance and perceived math ability, which could be discouraging women to study in science fields. Having a parent who works on a science related occupation could help reduce such barriers by potential role modeling effects or specific parental investments in STEM, which could help reduce gender stereotypes. 


\section{References}

Beede, D. N., Julian, T. A., Langdon, D., McKittrick, G., Khan, B. \& Doms, M. E. (2011). Women in STEM: A gender gap to innovation. Economics and Statistics Administration Issue Brief No. 04-11. Available at SSRN: https://ssrn.com/abstract=1964782 or http://dx.doi.org/10.2139/ssrn.1964782

Bertrand, M. (2010). New perspectives on gender. Handbook of Labor Economics, 4b, 1545-1592.

Black, S. E. \& Spitz-Oener, A. (2009). Explaining women's success: Technological change and the skill content of women's work. Review of Economics and Statistics, 92, 187-194.

Bureau of Labor Statistics, (2014). STEM 101: Intro to tomorrow's jobs. Occupational Outlook Quarterly, Spring 2014.

Card, D. \& Payne, A. A. (2017). High school choices and the gender gap in STEM. NBER Working paper 23769. Available at: http://www.nber.org/papers/w23769.pdf

Cheng, A., Kopotic, K. \& Zamarro, G. (2017). Can parents' growth mindset and role modeling address STEM gender gaps?. EDRE Working paper 2017-07. Available at: https://papers.ssrn.com/sol3/papers.cfm?abstract_id=2920623

Harackiewicz, J.M., Rozek, C.S., Hulleman, C.S., \& Hyde, J.S. (2012). Helping paren ts to motivate adolescents in mathematics and science: An experimental test of a utility-value intervention. Psychological Science, 23(8), 899-906.

Giannelli, G., \& Rapallini, C., (2017). The intergenerational transmission of math culture. (IZA Discussion Paper No. 10622). Bonn, Germany: Institute of Labor Economics 
Goldin, C., Lawrence, F. K. \& Kuziemko, I. (2006). The homecoming of American college women: The reversal of the college gender gap. Journal of Economic Perspectives, 20(4), 133-156.

Guiso, L., Monte, F., Sapienza, P. \& Zingales, L. (2008). Culture, gender and math. Science, 320(5880), 1164-1165.

Li, P. \& Stafford, F. P. (2017). How important are parental occupations to the new generation's occupation mobility?. Working Paper, Economic Behavior Program, Institute for Social Research, November 2017.

Nierderle, M., \& Vesterlund, L. (2010). Explaining the gender gap in math test scores: The role of competition. Journal of Economic Perspectives, 24(2), 129-144.

Nix, S., Perez-Felkner, L., Thomas, K., (2015). Perceived mathematical ability under challenge: a longitudinal perspective on sex segregation among STEM degree fields. Frontiers in Psychology, 6(530).

Nollenberger, N., \& Rodriguez-Planas, N., (2017). Let the girls learn! It is not only about math...it's about gender social norms. IZA Discussion Paper No. 103625. Available at: https://ssrn.com/abstract=2940615.

Perez-Felkner, L., Nix, S., Thomas, K. (2017). Gendered Pathways: How Mathematics Ability Beliefs Shape Secondary and Postsecondary Course and Degree Field Choices. Frontiers in Psychology, 8:386.

Robinson, J.P., \& Lubienski, S.T. (2011). The development of gender achievement gaps in mathematics and reading during elementary and middle school: Examining direct cognitive assessments and teacher ratings. American Educational Research Journal, 48(2), 268-302. 
Weinberger, C. J. (2005). Is the science and engineering workforce drawn from the far upper tail of the math ability distribution?, Mimeo. Available at: http://econ.ucsb.edu/ weinberg/uppertail.pdf. 